(C) 1983. The Genetical Society of Great Britain

\title{
GYNODIOECY IN PLANTAGO LANCEOLATA L. II INHERITANCE OF THREE MALE STERILITY TYPES*
}

\author{
J. M. M. VAN DAMME + \\ Department of Genetics, University of Groningen, Biology Centre, Kerklaan 30, \\ 9751 NN Haren, The Netherlands
}

Received 5.i.83

\section{SUMMARY}

Inheritance of male sterility has been studied in Plantago lanceolata. Crosses between plants, obtained from a $50 \mathrm{~m}^{2}$ area, yielded the entire array of possible sex phenotypes. Emphasis is put on nuclear inheritance of two nuclear-cytoplasmically determined male sterility types. In both types multiple interacting genes are involved. For MS1 a combination of two recessive and three dominant male sterility genes is proposed, for MS2 three recessives. These are minimum estimates as the exact numbers could not be determined. One of the loci for MS2 is probably linked to the self-incompatibility locus. Not all results can be explained this way, which emphasizes the complexity of nuclear inheritance. Intermediates between the completely male steriles of both types and hermaphrodites constitute two continuous series, each consisting of multiple genotypes with overlapping phenotypes. Segregation patterns indicate genetic determination by incomplete dominance at the male sterility loci. A third male sterility type (MS3) is described whose expression appears to be independent of plasmon type. Preliminary results indicate two duplicate recessive male sterility genes. The stability of the complexity of nuclear inheritance for gynodioecy is discussed.

\section{INTRODUCTION}

A major obstacle for understanding how male sterile plants are maintained in gynodioecious species, is the limited knowledge of the inheritance of this breeding system. From theoretical studies the extent of the disadvantage of being male sterile in a hermaphrodite population is known to depend upon the mode of inheritance. Requirements for the maintenance of male steriles are different in the case of nuclear-cytoplasmic inheritance (Charlesworth, 1981; Delannay et al., 1981) and in special cases in which only nuclear gene(s) or the plasmon type determine sex (Lewis, 1941; Lloyd, 1974). Particularly with nuclear-cytoplasmic inheritance, knowledge of the genetics is indispensable for determining the mechanism by which sex polymorphism is maintained.

Ross (1978) has surveyed most genetic studies on wild species and concluded that monogenic inheritance has hardly been found. Inheritance of male sterility was either claimed to be digenic or complex with cytoplasmic effects. It was argued by Charlesworth (1981) that nuclear-cytoplasmic models are likely to fit most data. Wild species clearly showing nuclearcytoplasmic inheritance are Nemophila menziesii (Ganders, 1978), Origanum vulgare (Kheyr-Pour, 1980,1981) and Mercurialis annua (Louis and Durand, 1978). The last case is noteworthy because it concerns a

${ }^{*}$ Grassland Species Research Group Publication no. 64

$\dagger$ Present address: Institute of Ecological Research, Department of Dune Research “Weevers' Duin", Duinzoom $20^{\mathrm{a}}, 3233$ EG Oostvoorne, The Netherlands 
dioecious species, and a rather complex mode of inheritance has been proposed. But in the first two cases uncertainties exist with respect to the contribution of nuclear genes. In other species the situation is less clear. Sometimes genetic models are based on only part of the results and often no specific models are offered. For numerous cultivated species, however, detailed reports on the genetics of male sterility have been published (Gottschalk and Kaul, 1974). These species usually have the advantage of having been inbred for a long time, which is convenient in this kind of study. The primary motive for conducting these studies has been economic interest, which may bias the picture of the distribution of the different modes of inheritance. Nevertheless, studies from this area are interesting because they show a wider range of modes of inheritance than has been encountered in wild species. Features which have only been described for cultivated species are gametophytic instead of sporophytic action of male sterility genes (Zea mays, Schwarz, 1951 and Buchert, 1961, for plasmon $\mathrm{N}$ and S respectively; Oryza sativa, Shinjyo, 1969) and permanent change in the plasmon induced by a nuclear gene (Zea mays, Rhoades, 1950; Vicia faba, Bond et al., 1966; Chenopodium quinoa, Simmonds, 1971). In the latter case the change can be in either direction depending on the species: male sterility inducing or fertility restoring.

In the present paper experiments will be described on the genetics of male sterility in Plantago lanceolata. Earlier studies on this subject by Correns (1906, 1908) and Bartlett (1913) yielded no clear answer. Ross (1969) proposed a digenic system in which male steriles were double recessive but noted that there should be some additional factor involved, probably of cytoplasmic nature (Ross, 1967). Apart from Bartlett, who studied a rather exceptional male sterility type, these authors were confronted with an almost continuous variation in sex expression from male sterile to hermaphrodite. Partial male sterile plants or intermediates occur to some extent in most gynodioecious species but are particularly marked in Plantago lanceolata. In a previous paper (Van Damme and Van Delden, 1982) it was shown that two complete series from sterile to fertile can be distinguished, differing in the morphology of male sterility. This difference appeared to be cytoplasmically determined and accordingly two plasmon types ( $R$ and $\mathbf{P})$ were distinguished. There are therefore two types of male steriles (MS1, MS2) and intermediates (IN1, IN2) corresponding with plasmon types $\mathbf{R}$ and $\mathbf{P}$. Regarding these male sterility types as different, it is clear that the cytoplasm is involved in the inheritance of both types as each is only expressed in the presence of its own plasmon type and not in that of the other. In the present paper the study of the genetics will be continued and will concentrate on the part the nucleus plays in the inheritance of the two male sterility types. Some attention will also be given to the intermediate sex phenotypes. Finally a third male sterility type will be described which is rare in nature, but which emerged during the study.

\section{Materials and methods}

The original parents were grown from seeds, collected from a $50 \mathrm{~m}^{2}$ area in the Westduinen which are situated in Goeree in the south-west of the Netherlands. In a previous paper this population was referred to as Wd and it was found to be polymorphic for plasmon type. A summary of 
the results presented here has been published in table 2 of that paper as evidence for the cytoplasmic determination of male sterile morphology (Van Damme and Van Delden, 1982). For crosses plants were kept in a greenhouse at a temperature of $21 / 17^{\circ} \mathrm{C}$ (day/night) with $16 \mathrm{hrs}$ light daily. Sometimes a $24 \mathrm{hrs}$ day was applied in order to induce flowering (Snyder, 1948). This treatment did not affect sex expression (unpublished results). As the species is protogynous and self-incompatible (Ross, 1973), crosses were made by bagging young spikes before female flowering and by keeping spikes from different plants in one bag during male flowering. Difficulties were encountered in crosses with some of the MS2 parents. Spikes of these MS2 plants had very weak scapes and often died after bagging. Controls were taken regularly by just bagging individual spikes. Rarely, some seeas were obtained which might have been due to contamination or incomplete self-incompatibility. Incompatibility between plants was concluded from lack of seed set after crossing. In addition, pollen tubes in the style of pollinated flowers were often examined for incompatible ends using fluorescence microscopy (Martin, 1959). Progenies were sown on moist filter paper. Spontaneous germination amounted to 66 per cent. After one week a tip of the non-germinating seeds was cut off on the side of the radicle, which resulted in a total germination of 98.5 per cent. Subsequent survival until flowering was 95 per cent. Plants were precultured in jiffy pots in a greenhouse for four weeks and then transplanted to an experimental garden except for weak plants $(5 \cdot 5$ per cent of the total) which were brought to flower in the greenhouse. Weak plants occurred after inbreeding, because several lethals and sublethals emerged during the study. This happened largely in families non-segrating for male sterility, but in two segregating families complications arose due to a sublethal gene and they will therefore not be discussed here. Sex was usually assessed by eye, but in some of the plants, more accurate observations were made to check the influence of the various breeding conditions on sex expression. Individual plants were observed during each treatment after successive transplantations. Five spikes $(i)$ were collected per plant in two out of three treatments and the proportion $(p)$ of sterile, intermediate and fertile anthers $(j)$, was estimated on each of them. In order to obtain a "maleness index" per plant, varying from male sterile to hermaphrodite on a $0-1$ scale, a value $(v) 0$ was given to sterile and 1 to fertile anthers. Intermediate anthers were assigned a value in between, depending on the number of forms distinguished (according to fig. 1 in Van Damme and Van Delden, 1982). The maleness index can then be calculated from $(1 / 5) \sum_{i} \sum_{j} p_{i} v_{j}$. In $\chi^{2}$ analyses, used for ratio testing, the correction for continuity was always applied when there was only one degree of freedom.

\section{STABILITY OF SEX PHENOTYPES}

In order to investigate the extent to which complete and partial male sterility are subject to instability, the sex phenotype of individual plants was observed in the summer of 1980 and 1981 in the garden and during the winter in between under greenhouse conditions. The group was drawn from $\mathrm{F} 1$ progenies of various crosses and consisted of plants from the following sex phenotypes: male steriles (MS), intermediates (IN) and hermaphrodites $(\mathrm{H})$, having plasmon $\mathrm{R}$ (MS1, IN1, H1) and the same 
phenotypes with plasmon $\mathrm{P}$ (MS2, IN2, H2). $\mathrm{H} 1$ and $\mathrm{H} 2$ were determined by descendance (Van Damme and Van Delden, 1982). The IN phenotypes were in this experiment subdivided into three subgroups: predominantly male sterile (IN-a), intermediate (IN-b) and predominantly hermaphrodite (IN-c). The same classification of IN phenotypes was used by Correns (1908). Approximately 15 plants were studied per phenotypic class and in total 73 plants with plasmon $R$ were studied, and 80 plants with plasmon $P$. The two plasmon types are treated as different series. In neither series could heterogeneity be detected in numbers per phenotypic class between breeding conditions $\left(\chi_{(8)}^{2}=8.58\right.$ and $\left.\chi_{(8)}^{2}=9 \cdot 26\right)$. There was, however, a considerable change between phenotypic classes. Even when the IN subgroups are taken together, the fraction of plants that change phenotype at least once during the experiment was 0.37 for the plasmon $\mathrm{R}$ series and 0.21 for plasmon $\mathrm{P}$. All changes except one were MS $\rightleftharpoons \mathrm{IN}$ and $\mathrm{IN} \rightleftharpoons \mathrm{H}$. The difference in the fraction between the two series was due to more IN $\rightleftharpoons \mathrm{H}$ changes in plants with plasmon $\mathrm{R}$. In both series the fraction of plants showing MS $\rightleftharpoons$ IN changes was $0 \cdot 12$.

In the plasmon $\mathrm{P}$ series a sub-hermaphrodite phenotype was initially distinguished between IN2-c and H2. It has a distinct appearance: symmetrical anthers, with a slightly elongated tip at the apex, its anther volume was about 20 per cent smaller than normal, but it shed all its pollen which was normally fertile. Ten individuals were selected from two different crosses. Later all plants from the one cross were assigned to IN2-b, and the others to $\mathrm{H} 2$ phenotype and no clear sub-hermaphrodite group remained. Therefore this phenotype was discarded and included in the IN2-c phenotype.

In the greenhouse and in the garden during 1981 sex phenotype was in addition assessed by a second, more accurate method. Of five spikes per plant fractions of anther types were estimated and converted into a "maleness index" as has been described in the previous section. This index has value 0 for complete male sterility and 1 for hermaphroditism. It should be noted that this measure is based on anther morphology which does not coincide with fertility. The maleness index has therefore no linear relationship with male fertility. In fig. 1 the index values for all plants of both series which were not male sterile or hermaphrodite during all three breeding conditions are shown. Male sterility expression appears nearly continuous for both types. It is clear that this method can also detect shifts within the phenotypic classes, distinguished by eye. Applying the signed rank test to the index values of the greenhouse and the garden yielded a just significant result for type $1(0.045<P<0.050)$ and a strongly significant result for type 2 sterility $(P<0 \cdot 01)$. In both cases male sterility expression was higher in the greenhouse. It was striking that the absolute difference between the index values of individual plants was significantly higher for type 1 compared with type $2(0.24$ versus $0.13, P<0.01)$. IN1 plants appear relatively more unstable while IN2 plants seem to react more strongly to environmental conditions. This was also found in an experiment with varying temperatures (unpublished results).

Although with a sensitive method male sterility expression can be shown to depend on environmental conditions, this has no consequences for the genetic study as $X^{2}$-analyses did not detect heterogeneity in the data. The results suggest that there are multiple genotypes with overlapping 


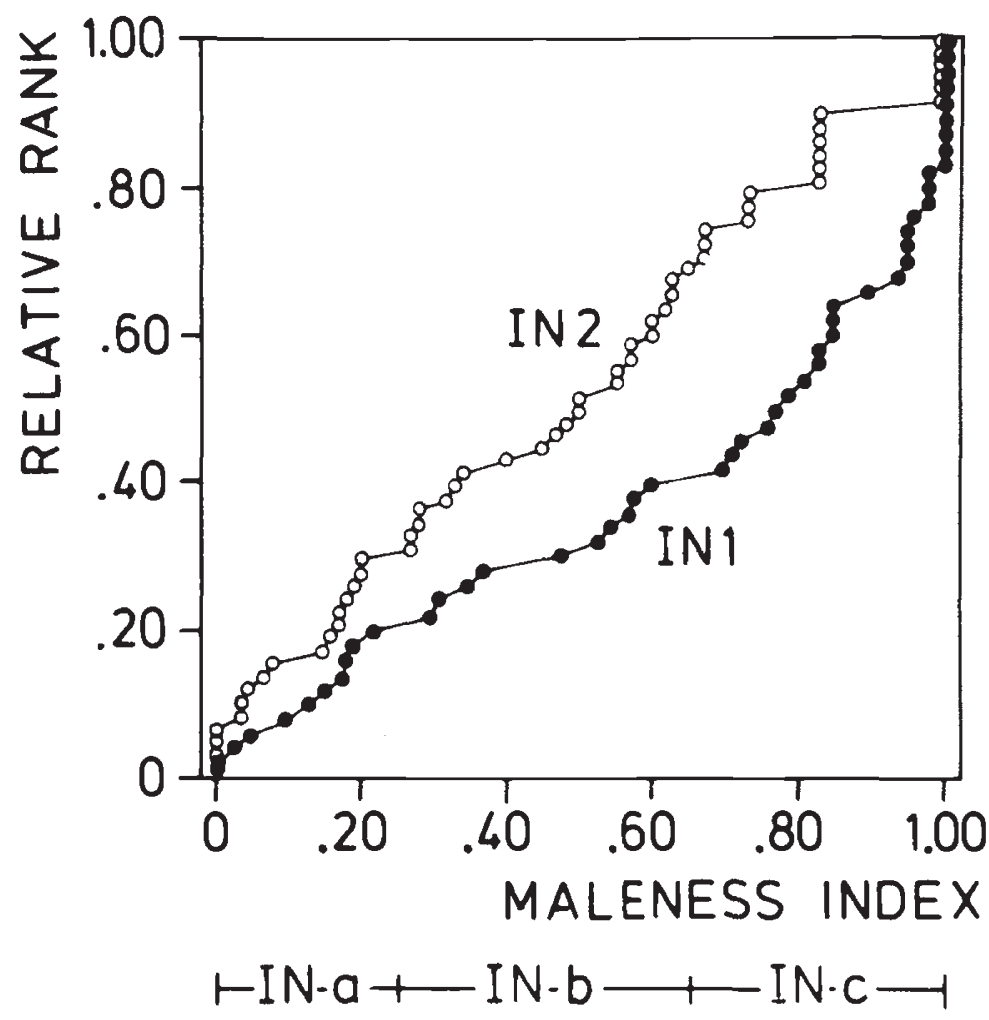

FIG. 1. Maleness index of plants with plasmon R (IN1) and plants with plasmon P (IN2) during the summer of 1981 in the experimental garden. Plants of each series are given a relative rank according to their index value for presentation purposes. Plants that flowered as either male sterile or hermaphrodite during all three treatments (see text) are excluded.

phenotypes, expressed as ranges on the maleness index scale. Even within the IN phenotypes more than one genotype probably exists. There is no way of knowing beforehand how phenotypes should be defined in order to avoid division of genotypes over phenotypic classes. A rather strict definition of complete male sterility has been used, allowing for only very rarely occurring weakly intermediate anthers.

\section{INHERITANCE OF TWO MALE STERILITY TYPES}

The two male sterility types which will be dealt with in this section, have been described in a previous paper (Van Damme and Van Delden, 1982). During the present study a third distinct male sterility type (MS3) turned up, segregating together with MS1 or MS2 depending on plasmon type. Data regarding this male sterility type are presented in the tables but will not be discussed until the next section. This also holds for dominance relations between the different sterility types.

Before discussing the genetics of the two male sterility types separately, it will be shown briefly that they are inherited differently. Of the twelve original parents chosen, four were MS1, two MS2, three $\mathrm{H} 1$ and three $\mathrm{H} 2$. 
TABLE 1

Reciprocal crosses between hermaphrodites. Results are given as numbers of male steriles in samples with size $n$. Significance levels in this and following tables: ${ }^{* * *} P<0.001 ;{ }^{* *} P<0.01$; ${ }^{*} P<0.05$

\begin{tabular}{|c|c|c|c|c|}
\hline Cross & Offspring & $\begin{array}{l}\text { Offspring of } \\
\text { reciprocal cross }\end{array}$ & $\begin{array}{c}\text { Heterogeneity } \\
\chi_{(1)}^{2}\end{array}$ & $\begin{array}{c}\text { Fraction of } \\
\text { successful } \\
\text { backcrosses } \\
\text { on father }\end{array}$ \\
\hline$H 1 \times H 1$ & $M S 1 / n$ & $M S 1 / n$ & & \\
\hline $141 \times 113$ & $0 / 64$ & $0 / 28$ & - & \\
\hline $141 \times 39$ & $1 / 49$ & $0 / 53$ & - & \\
\hline $113 \times 39$ & $0 / 18$ & $0 / 79$ & - & \\
\hline $\mathrm{H} 2 \times \mathrm{H}_{2}$ & $M S 2 / n$ & $M S 2 / n$ & & \\
\hline $17 \times 23$ & $1 / 54$ & $5 / 54$ & $2 \cdot 82$ & \\
\hline $17 \times 18$ & $0 / 53$ & $0 / 51$ & - & \\
\hline $23 \times 18$ & $0 / 52$ & $0 / 51$ & - & \\
\hline $\mathrm{H} 1 \times \mathrm{H}_{2}$ & $M S 1 / n$ & $M S 2 / n$ & & \\
\hline $141 \times 17$ & $17 / 101$ & $0 / 83$ & $15 \cdot 39 * * *$ & $10 / 10^{* * *+}$ \\
\hline $141 \times 23$ & $18 / 103$ & $6 / 100$ & $6 \cdot 41^{*}$ & $16 / 16^{* * *}$ \\
\hline $113 \times 23$ & $27 / 93$ & $4 / 87$ & $18 \cdot 83^{* * *}$ & $12 / 12^{* * *}$ \\
\hline $113 \times 18$ & $11 / 66$ & $0 / 84$ & $15 \cdot 19 * * *$ & $9 / 9 * *$ \\
\hline $39 \times 17$ & $73 / 105$ & $3 / 106$ & $101 \cdot 81^{* * *}$ & $19 / 19^{* * *}$ \\
\hline $39 \times 23$ & $78 / 85$ & $17 / 111$ & $112 \cdot 64^{* * *}$ & $9 / 9 * *$ \\
\hline $39 \times 18$ & $75 / 89$ & $0 / 80$ & $121 \cdot 21^{* * *}$ & $10 / 10^{* * *}$ \\
\hline \multicolumn{5}{|c|}{ Families $143(\mathrm{H} 1-141 \times \mathrm{H} 2-23)$ and $144(\mathrm{H} 2-23 \times \mathrm{H} 1-141)$} \\
\hline $143-1 \times 144-1$ & $0 / 79$ & $8 / 83$ & $8.01^{* *}$ & \\
\hline $143-2 \times 144-5$ & $1 / 72$ & $7 / 76$ & $5 \cdot 36^{*}$ & \\
\hline
\end{tabular}

† Significance level denotes probability that the original cross is half-compatible.

In table 1 the fractions of MS in the progenies of all reciprocal crosses between hermaphrodites made in this study are presented. Crosses between plants with the same plasmon type yielded no differences between reciprocals, often no male steriles at all. On the other hand, reciprocal crosses between plasmon types were always significantly different both in the first and in the second generation. If the same nuclear genes are responsible for both male sterility types, no differences in these crosses would be expected. A complication, however, may be the self-incompatibility system. Differences between reciprocals can also result from linkage of a male sterility gene and the $S$-locus if the cross is half-compatible. This can be tested by backcrossing some of the offspring on the father. If the original cross was half-compatible, half of the backcrosses are expected to be unsuccessful because of the nature of the self-incompatibility system (Ross, 1973). All first generation crosses between $\mathrm{H} 1$ and $\mathrm{H} 2$ plants were tested and appeared fully compatible (table 1). Apparently the nuclear genes determining male sterility are at least partly different for each type.

\section{(i) Male sterility type 1}

All possible crosses including the original MS1 and $\mathrm{H} 1$ plants and most crosses between these and the $\mathrm{H} 2$ plants have been made. Progenies of 
six crosses were used for the second generation. The results are given in tables 2 and 4 . The first generation (table 2) shows a variety of ratios of MS1 versus other phenotypes, ranging from $1: 0$ to $0: 1$. Most striking are the MS $1 \times \mathrm{H} 2$ crosses which yielded no hermaphrodites at all and only very few intermediates, the rest being male sterile. Similar results have been obtained in three second generation families derived from these crosses (table 4) and in some crosses involving plant H1-39 (table 2). These results taken together, give $1497 \mathrm{MS} 1,41 \mathrm{IN} 1$ and $2 \mathrm{H}$ plants. The two hermaphrodites were not tested and were possibly due to contamination. The occurrence of IN1 plants was not correlated with a particular male or female parent, and is regarded as an expression of overlapping phenotypic ranges of sex genotypes as was referred to in the previous section.

The results can be explained by a multiple gene system, consisting of a number of male sterility genes with either recessive or dominant action of the sterility alleles. They will respectively be designated as $m r$ and $M r$ genes. Table 3 lists the proposed genotypes of the parents of table 2. Only plants with plasmon $\mathrm{R}$ that are homozygous recessive for all $m r$ genes and at least heterozygous for the dominant allele at all $M r$ loci have phenotype MS1. The mode of interaction is such that the male sterility genotype at each locus is necessary for the MS1 phenotype, but in itself not sufficient. Expected ratios in tables 2 and 4 have been calculated on the basis of this general model. If plants are crossed which are homozygous for the sterility alleles at the $m r$ loci, the genetic system will show up as a set of dominant male sterility genes and vice versa. This explains in general terms the occurrence of the "reverse" ratios $1: 3$ and $3: 1$ in table 2. All parents and their progenies in this table have plasmon $\mathrm{R}$ except for the three original $\mathrm{H} 2$ parents $\mathrm{H} 2-17, \mathrm{H} 2-23$ and $\mathrm{H} 2-18$ which can in principle have any genotype with respect to type 1 sterility. It appears, however, from the MS $1 \times \mathrm{H} 2$ crosses that they all have nuclear genotypes corresponding to a male sterile phenotype in plasmon $\mathrm{R}$. Because the $\mathrm{H} 2$ plants yield higher fractions of MS1 when crossed with $\mathrm{H} 1-141$ or $\mathrm{H} 1-113$ than do the plants MS1-128, MS1-7, MS1-14 and MS1-134 (table 2), the conclusion can be drawn that they have an even "more sterile" nuclear genotype than the MS1 plants themselves. This can only be due to their having fewer wild type alleles at the $\mathrm{Mr}$ loci, as both the MS1 and $\mathrm{H} 2$ plants must be homozygous recessive for the $m r$ genes. Of the three $\mathrm{H} 1$ parents, only plant $\mathrm{H} 1-39$ is homozygous recessive for the $m r$ genes and necessarily homozygous wild type for at least one $M r$ gene, otherwise it would be male sterile. The other two plants, H1-141 and H1-113, never giving "reverse" ratios, are heterozygous for the $m r$ genes. They cannot be homozygous wild type for one of these genes, nor can any of the other parents in table 2 , because they are capable of segregating MS1 at least in some crosses.

The data in table 2 provide some information on the number of loci involved. In crosses with $\mathrm{H} 1-141$ and $\mathrm{H} 1-113$, variation at the $m r$ loci should always be expressed, as all other parents are homozygous recessive at these loci. On the other hand, variation at the $M r$ loci can easily be hidden in crosses with the $\mathrm{H} 2$ plants, especially with $\mathrm{H} 2-23$ which is homozygous dominant at all these loci, as will be shown (cf. table 2). Ratios which are possible in this kind of cross, therefore, provide an indication of the number of $m r$ loci. The four crosses between H1-141, H1-113 and H2 plants in table 2, are compatible with $1: 3$ and also, except for $\mathrm{H} 1-113 \times$ 
TABLE 2

First generation of crosses with female parents having plasmon $R$

\begin{tabular}{|c|c|c|c|c|c|c|c|c|c|c|}
\hline \multirow[b]{2}{*}{ Cross } & \multicolumn{4}{|c|}{ Offspring } & \multicolumn{4}{|c|}{ MS1 :(IN1 + H1 + MS3) } & \multicolumn{2}{|c|}{ MS1:IN1:H1 } \\
\hline & MS1 & IN1 & $\mathrm{H} 1$ & MS3 & Ratio & $\chi_{(1)}^{2}$ & Ratio & $\chi_{(1)}^{2}$ & Ratio & $\chi_{(2)}^{2}$ \\
\hline \multicolumn{11}{|l|}{$M S 1 \times H 1$} \\
\hline $128 \times 141$ & 1 & 16 & 84 & & $1: 31$ & 0.90 & $1: 15$ & $3.91^{*}$ & $1: 5: 26$ & 1.52 \\
\hline $128 \times 113$ & 4 & 23 & 66 & & $1: 15$ & 0.32 & $1: 7$ & $4.99 *$ & $1: 4: 11$ & 0.63 \\
\hline $128 \times 39 \dagger$ & 76 & 23 & 2 & & $3: 1$ & 0.00 & & & $12: 3: 1$ & $3 \cdot 82$ \\
\hline $7 \times 141$ & 1 & 15 & 86 & & $1: 31$ & 0.92 & $1: 15$ & $3.98^{*}$ & $1: 5: 26$ & 1.67 \\
\hline $7 \times 113$ & 4 & 26 & 67 & & $1: 15$ & 0.43 & $1: 7$ & $5 \cdot 48^{*}$ & $1: 4: 11$ & 0.83 \\
\hline $7 \times 39$ & 82 & 19 & 1 & & $3: 1$ & $1 \cdot 31$ & & & $12: 3: 1$ & 4.93 \\
\hline $14 \times 141$ & 9 & 37 & 51 & & $1: 7$ & 0.65 & $1: 15$ & 1.05 & $1: 3: 4$ & 0.95 \\
\hline $14 \times 113$ & 8 & 38 & 50 & & $1: 7$ & $1 \cdot 17$ & $1: 15$ & 0.40 & $1: 3: 4$ & 1.53 \\
\hline $14 \times 39$ & 88 & 7 & 0 & & $1: 0$ & - & & & & \\
\hline $134 \times 141$ & 2 & 27 & 69 & & $1: 15$ & $2 \cdot 29$ & $1: 7$ & $8.87^{* *}$ & $1: 4: 11$ & 3.07 \\
\hline $134 \times 113$ & 7 & 22 & 67 & & $1: 15$ & 0.04 & $1: 7$ & 1.93 & $1: 4: 11$ & 0.35 \\
\hline $134 \times 39 t$ & 98 & 0 & 0 & & $1: 0$ & - & & & & \\
\hline \multicolumn{11}{|l|}{$M S 1 \times H 2$} \\
\hline $128 \times 17$ & 94 & 2 & 0 & & $1: 0$ & - & & & & \\
\hline $7 \times 17$ & 72 & 3 & 0 & & $1: 0$ & - & & & & \\
\hline $7 \times 18^{\dagger}$ & 98 & 0 & 0 & & $1: 0$ & - & & & & \\
\hline $14 \times 17 \dagger$ & 59 & 0 & 0 & & $1: 0$ & - & & & & \\
\hline $14 \times 23 \dagger$ & 67 & 0 & 0 & & $1: 0$ & - & & & & \\
\hline $14 \times 18$ & 85 & 1 & 0 & & $1: 0$ & - & & & & \\
\hline $134 \times 17$ & 68 & 0 & 0 & & $1: 0$ & - & & & & \\
\hline $134 \times 23$ & 58 & 0 & 0 & & $1: 0$ & - & & & & \\
\hline \multicolumn{11}{|l|}{$H 1 \times H 1$} \\
\hline $141 \times 113 \ddagger$ & 0 & 19 & 73 & & $0: 1$ & - & & & & \\
\hline $141 \times 39 \ddagger$ & 1 & 9 & 92 & & $0: 1$ & - & & & & \\
\hline $113 \times 39 \ddagger$ & 0 & 15 & 82 & & $0: 1$ & - & & & & \\
\hline \multicolumn{11}{|l|}{$H 1 \times H 2$} \\
\hline $141 \times 17$ & 17 & 7 & 77 & & $1: 3$ & $3 \cdot 17$ & $1: 7$ & 1.36 & & \\
\hline $141 \times 23 \dagger$ & 18 & 8 & 77 & & $1: 3$ & 2.72 & $1: 7$ & 1.90 & & \\
\hline $113 \times 23$ & 27 & 8 & 28 & 30 & $1: 3$ & 0.61 & $1: 7$ & $21 \cdot 75^{* * *}$ & & \\
\hline $113 \times 18$ & 11 & 6 & 42 & 7 & $1: 3$ & $2 \cdot 02$ & $1: 7$ & 0.70 & & \\
\hline $39 \times 17$ & 73 & 25 & 7 & & $3: 1$ & 1.40 & & & $12: 3: 1$ & $1 \cdot 88$ \\
\hline $39 \times 23$ & 78 & 7 & 0 & & $1: 0$ & - & & & & \\
\hline $39 \times 18$ & 75 & 10 & 4 & & $3: 1$ & 3.60 & & & $12: 3: 1$ & $4 \cdot 14$ \\
\hline
\end{tabular}

$\dagger$ Plants from this cross served as parents for the second generation.

$\ddagger$ Results of reciprocals have been added.

$\mathrm{H} 2-23$, with $1: 7$. It follows that $\mathrm{H} 1-113$ is heterozygous for two recessive male sterility genes and $\mathrm{H} 1-141$ for two or three. This gives a minimum number of two recessives $\left(m r_{1}, m r_{2}\right)$, but it may be more (up to five) as it cannot be inferred from the data whether $\mathrm{H} 1-141$ and $\mathrm{H} 1-113$ are heterozygous at the same loci. In crosses without these two plants, only variation at the $M r$ loci is expressed. Of particular interest are crosses between H1-39 and the MS1 and H2 plants. Proposed genotypes for these plants are in table 3 . It has already been noted that one dominant male sterility gene $\left(\mathrm{Mr}_{3}\right)$ is necessary to explain H1-39 not being male sterile. Crosses between $\mathrm{H} 1-39$ and either the MS1 or $\mathrm{H} 2$ plants result in both $3: 1$ and 1:0 ratios. This indicates the existence of two additional loci $\left(M r_{4}, M r_{5}\right)$, 
TABLE 3

Proposed genotypes for the male sterility genes of the parents of the crosses in table 2. The $\mathrm{mr}$ and Mr genes have male sterility alleles with recessive and dominant action respectively. For two plants the genotypes for $\mathrm{Mr}_{4}$ and $\mathrm{Mr}_{5}$ is left open

\begin{tabular}{ll}
\hline \multicolumn{1}{c}{ Plant number } & \multicolumn{1}{c}{ Male sterility genotype } \\
\hline MS1-14, MS1-134, H2-23 & $m r_{1} m r_{1}, m r_{2} m r_{2}, M r_{3} M r_{3}, M r_{4} M r_{4}, M r_{5} M r_{5}$ \\
H2-17, H2-18 & $m r_{1} m r_{1}, m r_{2} m r_{2}, M r_{3} M r_{3}, M r_{4} M r_{4}, M r_{5}+$ \\
MS1-7, MS1-128 & $m r_{1} m r_{1}, m r_{2} m r_{2}, M r_{3} M r_{3}, M r_{4}+, M r_{5} M r_{5}$ \\
H1-39 & $m r_{1} m r_{1}, m r_{2} m r_{2},++, M r_{4}+, M r_{5}+$ \\
H1-113, H1-141 & $m r_{1}+, m r_{2}+,++$, \\
\hline
\end{tabular}

with H1-39 heterozygous at both, MS1-7 and MS1-128 heterozygous at one, $\mathrm{H} 2-17$ and $\mathrm{H} 2-18$ at the other and MS1-14, MS1-134 and $\mathrm{H} 2-23$ homozygous dominant at both (table 3). One extra locus instead of two is not sufficient because then it cannot be explained how MS1 $\times \mathrm{H} 2$ crosses always give a 1:0 ratio (table 2). Alternative though more complicated explanations are possible: $\mathbf{M r}_{4}$ and $\mathrm{Mr}_{5}$ can, for instance, be replaced by three recessive male sterility genes which each give male sterility independently from each other, provided that $m r_{1}, m r_{2}$ and $M r_{3}$ are in the sterile condition. Although rather arbitrarily, preference is given in this presentation to the former possibility. The proposed three $\mathbf{M r}$ genes fit the ratios in table 2 of crosses between plants that are homozygous recessive at the $m r$ loci, but not all those with plants H1-141 and H1-113. Assuming that these two plants are heterozygous at $m r_{1}$ and $m r_{2}$ and homozygous wild type at $\mathrm{Mr}_{3}$ (table 3), the crosses between them and those with H1-39 and the $\mathrm{H} 2$ plants are explained according to the ratios in table 2 . In crosses with MS1 plants, however, the ratios 1:7, 1:15 and 1:31 have been obtained, which are only partly explained by the double backcross at $m r_{1}$ and $m r_{2}$. Additional backcrosses on dominant loci are necessary (with H1-141 and H1-113 being homozygous wild type). In order to explain all ratios in the first column of table 2 simultaneously two additional $M r$ loci seem required but this will not be described in detail as there are many possibilities.

The second generation families in table 4 generally support the model proposed above. The first three families originated from $\mathrm{MS} 1 \times \mathrm{H} 2$ crosses, yielding 100 per cent MS1. They consist of backcrosses on the father and again only MS1 plants were obtained. In family 132 this is according to expectation as $\mathrm{H} 2-23$ is homozygous for all sterility genes, but in families 135 and 133 backcrosses on the father should give either $1: 0$ or $3: 1$, due to heterozygosity at the $\mathrm{Mr}_{5}$ locus of the recurrent parent (table 3). The probability that all five female parents of these backcrosses are homozygous for $\mathrm{Mr}_{5}$ so that they would give 1:0 ratios, is 0.03 . Family 143 was derived from the plants $\mathrm{H} 1-141$ and $\mathrm{H} 2-23$, having respectively the most fertile and the most sterile nuclear genotype of the original parents (table 2). Backcrosses of MS1 progeny on $\mathrm{H} 2-23$ also gave a 1:0 ratio as expected. In the $\mathrm{H} 1 \times \mathrm{H} 2$ crosses in this family, the $\mathrm{H} 2$ parents come from the reciprocal cross $\mathrm{H} 2-23 \times \mathrm{H} 1-141$ and they can have a variety of genotypes. The H1 parents, however, are at least heterozygous at one $m r$ locus and therefore the crosses can give any fraction MS1 of $\frac{1}{2}$ and lower, including 
TABLE 4

Second generation families with plasmon $R$, derived from crosses in table 2

\begin{tabular}{|c|c|c|c|c|c|c|c|c|c|c|}
\hline \multirow[b]{2}{*}{ Cross } & \multicolumn{4}{|c|}{ Offspring } & \multicolumn{4}{|c|}{ MS1 : (IN1 + H1 + MS3) } & \multicolumn{2}{|c|}{ MS1:IN1 : H1 } \\
\hline & MS1 & IN1 & $\mathrm{H} 1$ & MS3 & Ratio & $x_{(1)}^{2}$ & Ratio & $x_{(1)}^{2}$ & Ratio & $x_{(2)}^{2}$ \\
\hline \multicolumn{11}{|c|}{ Family 135 (MS1-7 $\times$ H2-18) } \\
\hline \multicolumn{11}{|c|}{$M S 1 \times H 2$} \\
\hline $135-1 \times 18$ & 76 & 0 & 0 & & $1: 0$ & - & & & & \\
\hline $135-2 \times 18$ & 78 & 0 & 0 & & $1: 0$ & - & & & & \\
\hline $135-2 \times 18$ & 72 & 0 & 0 & & $1: 0$ & - & & & & \\
\hline \multirow{2}{*}{\multicolumn{11}{|c|}{$\begin{array}{l}\text { Family } 133(M S 1-14 \times H 2-17) \\
\text { MS1 } \times H 2\end{array}$}} \\
\hline & & & & & & & & & & \\
\hline $133-1 \times 17$ & 105 & 3 & 1 & & $1: 0$ & - & & & & \\
\hline $133-1 \times 17$ & 80 & 10 & 0 & & $1: 0$ & - & & & & \\
\hline \multirow{2}{*}{\multicolumn{11}{|c|}{$\begin{array}{l}\text { Family } 132(M S 1-14 \times H 2-23) \\
\quad M S 1 \times H 2\end{array}$}} \\
\hline & & & & & & & & & & \\
\hline $132-3 \times 23$ & 48 & 0 & 0 & & $1: 0$ & - & & & & \\
\hline $132-5 \times 23$ & 72 & 0 & 0 & & $1: 0$ & - & & & & \\
\hline \multirow{2}{*}{\multicolumn{11}{|c|}{$\begin{array}{l}\text { Family } 143(H 1-141 \times H 2-23) \\
\text { MS } 1 \times H 2\end{array}$}} \\
\hline & & & & & & & & & & \\
\hline $143-7 \times 23$ & 75 & 6 & 1 & & $1: 0$ & - & & & & \\
\hline $\begin{aligned} 143-21 & \times 23 \\
H 1 & \times H 2\end{aligned}$ & 79 & 2 & 0 & & $1: 0$ & - & & & & \\
\hline $143-1 \times 144-1$ & 0 & 1 & 56 & 22 & $1: 31$ & 1.62 & $1: 15$ & $4 \cdot 25^{*}$ & & \\
\hline $143-2 \times 144-5$ & 1 & 10 & 61 & & $1: 31$ & 0.26 & $1: 15$ & $2 \cdot 13$ & $1: 5: 26$ & 0.94 \\
\hline \multirow{2}{*}{\multicolumn{11}{|c|}{$\begin{array}{l}\text { Family } 57(M S 1-128 \times H 1-39) \\
\text { MS1 } \times H 1\end{array}$}} \\
\hline & & & & & & & & & & \\
\hline $57-3 \times 39$ & 34 & 30 & 7 & & $3: 5$ & $2 \cdot 84$ & $1: 1$ & 0.06 & $3: 4: 1$ & $3 \cdot 29$ \\
\hline $57-4 \times 39$ & 25 & 38 & 7 & & $3: 5$ & 0.03 & $1: 1$ & $5 \cdot 16^{*}$ & $3: 4: 1$ & 0.67 \\
\hline $57-5 \times 39$ & 38 & 24 & 6 & & $1: 1$ & 0.72 & $3: 5$ & $9 \cdot 04^{* *}$ & $4: 3: 1$ & 1.29 \\
\hline $57-9 \times 39$ & 25 & 29 & 7 & & $3: 5$ & 0.19 & $1: 1$ & $1 \cdot 64$ & $3: 4: 1$ & $0 \cdot 32$ \\
\hline $\begin{array}{l}57-9 \times 57-98 \\
H 1 \times H 1\end{array}$ & 36 & 29 & 11 & & $3: 5$ & 2.75 & $1: 1$ & $0 \cdot 12$ & $3: 4: 1$ & $4 \cdot 34$ \\
\hline $\begin{array}{r}H 1 \times H 1 \\
57-81 \times 39\end{array}$ & 18 & 39 & 10 & & $1: 3$ & 0.05 & $5: 11$ & 0.41 & $1: 2: 1$ & 3.72 \\
\hline $39 \times 57-81$ & 21 & 33 & 16 & & $1: 3$ & 0.69 & $5: 11$ & 0.01 & $1: 2: 1$ & 0.94 \\
\hline \multirow{2}{*}{\multicolumn{11}{|c|}{$\begin{array}{l}\text { Family } 63(M S 1-134 \times H 1-39) \\
\text { MS1 } \times H 1\end{array}$}} \\
\hline & & & & & & & & & & \\
\hline $63-1 \times 39$ & 37 & 25 & 1 & & $1: 1$ & 1.59 & $3: 5$ & $11 \cdot 23^{* * *}$ & & \\
\hline $63-3 \times 39$ & 40 & 30 & 9 & & $1: 1$ & 0.00 & $3: 5$ & $5 \cdot 27^{*}$ & & \\
\hline $63-4 \times 39$ & 45 & 25 & 1 & & $1: 1$ & $4.56^{*}$ & $3: 5$ & $19 \cdot 20^{* * *}$ & & \\
\hline
\end{tabular}

$\frac{1}{32}$ as was found (table 4). More critical information comes from two families involving H1-39. The original cross of family 57 was MS1-128 $\times \mathrm{H} 1-39$ which gave a 3:1 ratio. Neglecting for a moment $M r_{5}$, the varying loci are $\mathrm{Mr}_{3}$ and $\mathrm{Mr}_{4}$ (table 3). From the cross result two MS1 genotypes $\mathrm{Mr}_{3}+$, $\mathrm{Mr}_{4} \mathrm{Mr}_{4}$ and $\mathrm{Mr}_{3}+, \mathrm{Mr}_{4}+$ which in backcrosses on H1-39 give a 1:1 and a 3:5 ratio respectively. The $\mathrm{H} 1$ plants from the cross are $\mathrm{Mr}_{3}+,++$ and should give $1: 3$ ratio with H1-39. All crosses in family 57 fit the expectations (table 4). The data are not sufficient to distinguish between two or three loci varying within one cross. $M r_{5}$ could easily be varying without being noticed because a $1: 1$ ratio would change into $3: 5$, and $3: 5$ into $9: 23$. In fact one cross, MS1-57-4 $\times$ H1-39 fits the latter ratio $\left(\chi_{(1)}^{2}=1.64\right)$. Most important in this family is the fact that no cross exceeds 50 per cent MS1 in its offspring, which is good evidence for the existence of the $\mathrm{Mr}_{3}$ 
locus. The existence of $M_{4}$ (and $M r_{5}$ ) is less certain. The results in this family can also be explained by $\mathrm{Mr}_{3}$ together with two independent recessives, as mentioned earlier. This model yields the same ratios except for the $1: 3$ which changes into a $5: 11$ (table 4). Further complications are indicated by the results with family 63, derived from MS1-134 $\times$ H1-39. This cross gave only MS1 plants in the offspring, which are divided into the same genotypes as in the previous family. The same arguments apply, but none of the three backcrosses on H1-39 fits a 3:5 ratio and only two fit the $1: 1$ ratio. Taking the segregation of $\mathrm{IN} 1$ plants into account the impression that family 63 is different from family 57 is strengthened. However, the IN1 phenotype will be treated separately.

(ii) Male sterility type 2

The genetics of the MS2 phenotype were examined by making all possible crosses involving the original MS2 and $\mathrm{H} 2$ plants and most of the crosses between these and the $\mathrm{H} 1$ plants (table 5). From three crosses a

TABLE 5

First generation of crosses with female parents having plasmon $P$. For chi-square values betwee. brackets see text

\begin{tabular}{|c|c|c|c|c|c|c|c|c|c|c|}
\hline \multirow[b]{2}{*}{ Cross } & \multicolumn{4}{|c|}{ Offspring } & \multicolumn{4}{|c|}{ MS2: (IN2 + H2) } & \multicolumn{2}{|c|}{ MS2: IN2:H2 } \\
\hline & MS2 & IN2 & $\mathrm{H} 2$ & MS3 & Ratio & $x_{(1)}^{2}$ & Ratio & $x_{(1)}^{2}$ & Ratio & $x_{(2)}^{2}$ \\
\hline \multicolumn{11}{|l|}{$M S 2 \times H 2$} \\
\hline $13 \times 17^{\dagger}$ & 20 & 14 & 6 & & $1: 3$ & $12 \cdot 03^{* * *}$ & $1: 1$ & 0.03 & & \\
\hline $13 \times 23$ & 18 & 34 & 24 & 28 & $1: 3$ & 0.02 & & & $1: 2: 1$ & 1.79 \\
\hline $13 \times 18$ & 1 & 14 & 72 & 9 & $0: 1$ & 一 & & & $0: 1: 7$ & 1.79 \\
\hline $43 \times 17$ & 40 & 33 & 35 & & $1: 3$ & $7 \cdot 72^{* *}$ & $1: 1$ & $6 \cdot 75^{* *}$ & & \\
\hline $43 \times 23$ & 21 & 48 & 36 & & $1: 3$ & $1 \cdot 15$ & & & $1: 2: 1$ & $5 \cdot 06$ \\
\hline $43 \times 18$ & 0 & 14 & 94 & & $0: 1$ & - & & & $0: 1: 7$ & 0.02 \\
\hline \multicolumn{11}{|l|}{$M S 2 \times H 1$} \\
\hline $13 \times 141$ & 9 & 29 & 37 & & $1: 7$ & $0 \cdot 00$ & $1: 3$ & $6 \cdot 08^{*}$ & $1: 3: 4$ & 0.05 \\
\hline $13 \times 39$ & 20 & 29 & 30 & & $1: 3$ & $0 \cdot 00$ & & & $1: 2: 1$ & $8 \cdot 11^{*}$ \\
\hline $43 \times 113$ & 24 & 27 & 61 & & $1: 3$ & 0.58 & & & $1: 2: 1$ & $54 \cdot 48^{* * *}$ \\
\hline $43 \times 39$ & 34 & 34 & 37 & & $1: 3$ & 2.67 & & & $1: 2: 1$ & $13 \cdot 21^{* *}$ \\
\hline \multicolumn{11}{|l|}{$H 2 \times H 2$} \\
\hline $17 \times 23 \ddagger$ & 6 & 47 & 55 & & $1: 15$ & 0.00 & $1: 7$ & $4 \cdot 15^{*}$ & $1: 3: 4$ & $5 \cdot 23$ \\
\hline $17 \times 18 \neq$ & 0 & 5 & 99 & & $0: 1$ & - & & & $0: 1: 31$ & 0.97 \\
\hline $23 \times 18 \ddagger$ & 0 & 4 & 86 & 13 & $0: 1$ & - & & & $0: 1: 15$ & $0 \cdot 50$ \\
\hline \multicolumn{11}{|l|}{$H 2 \times H 1$} \\
\hline $17 \times 141$ & 0 & 16 & 67 & & $1: 31$ & 1.75 & $1: 15$ & $4.52^{*}$ & $1: 5: 26$ & $3 \cdot 31$ \\
\hline $17 \times 39 \dagger$ & 3 & 39 & 64 & & $1: 15$ & 1.57 & $1: 7$ & $8 \cdot 20^{* *}$ & $1: 4: 11$ & $\begin{array}{l}8 \cdot 96^{*} \\
(2 \cdot 45)\end{array}$ \\
\hline $23 \times 141 \dagger$ & 6 & 26 & 68 & & $1: 31$ & $1 \cdot 86$ & $1: 15$ & 0.01 & $1: 4: 11$ & 0.06 \\
\hline $23 \times 113$ & 4 & 32 & 28 & 23 & $1: 15$ & 0.07 & $1: 7$ & $1 \cdot 75$ & $1: 3: 4$ & $5 \cdot 17$ \\
\hline $23 \times 39$ & 17 & 54 & 40 & & $1: 15$ & $14 \cdot 06^{* * *}$ & $1: 7$ & 0.57 & $1: 3: 4$ & $\begin{array}{c}8 \cdot 71^{*} \\
(1 \cdot 11)\end{array}$ \\
\hline $18 \times 113$ & 0 & 2 & 68 & 14 & $0: 1$ & - & & & $0: 1: 31$ & 0.02 \\
\hline $18 \times 39$ & 0 & 13 & 67 & & $0: 1$ & - & & & $0: 1: 31$ & $\begin{array}{l}45 \cdot 52^{* * *} \\
(2.68)\end{array}$ \\
\hline
\end{tabular}

+ Plants from this cross served as parents for the second generation.

$¥$ Results of reciprocals have been added. 
TABLE 6

Second generation families with plasmon $P$. For chi-square values between brackets see text

\begin{tabular}{|c|c|c|c|c|c|c|c|c|c|c|}
\hline \multirow[b]{2}{*}{ Cross } & \multicolumn{4}{|c|}{ Offspring } & \multicolumn{4}{|c|}{ MS2: $(\mathrm{IN} 2+\mathrm{H} 2)$} & \multicolumn{2}{|c|}{ MS2: IN2: H2 } \\
\hline & MS2 & IN2 & $\mathrm{H} 2$ & MS3 & Ratio & $x_{(1)}^{2}$ & Ratio & $x_{(1)}^{2}$ & Ratio & $x_{(2)}^{2}$ \\
\hline \multicolumn{11}{|c|}{$\begin{array}{c}\text { Family } 70(\text { MS } 2-13 \times H 2-17) \\
\text { MS } 2 \times H 2\end{array}$} \\
\hline $70-4 \times 17$ & 42 & 35 & 20 & & $1: 1$ & 1.49 & & & & \\
\hline $70-5 \times 17$ & 38 & 21 & 3 & & $1: 1$ & $2 \cdot 73$ & & & & \\
\hline $70-6 \times 17$ & 25 & 16 & 3 & & $1: 1$ & 0.57 & & & & \\
\hline \multicolumn{11}{|c|}{$\begin{array}{l}\text { Family } 140(H 2-17 \times H 1-39) \\
\quad \text { MS } 2 \times H 2\end{array}$} \\
\hline $140-1 \times 17$ & 9 & 46 & 20 & & $1: 3$ & $6 \cdot 08^{*}$ & $1: 8$ & 0.00 & $2: 9: 7$ & $4 \cdot 86$ \\
\hline $\begin{array}{r}140-65 \times 17 \\
M S 2 \times H 1\end{array}$ & 30 & 36 & 7 & & $1: 3$ & $9 \cdot 25^{* *}$ & $7: 11$ & 0.07 & $7: 9: 2$ & 0.25 \\
\hline $140-1 \times 39$ & 10 & 47 & 30 & & $1: 3$ & $7 \cdot 76^{* *}$ & $1: 8$ & 0.00 & $2: 9: 7$ & 0.73 \\
\hline $\begin{array}{r}140-65 \times 39 \\
H 2 \times H 2\end{array}$ & 31 & 43 & 4 & & $1: 3$ & $8 \cdot 27^{* *}$ & $7: 11$ & 0.00 & $7: 9: 2$ & $2 \cdot 94$ \\
\hline $140-5 \times 17$ & 16 & 39 & 17 & & $1: 7$ & $5 \cdot 37^{*}$ & $7: 29$ & $0 \cdot 20$ & $7: 16: 13$ & 4.93 \\
\hline $17 \times 140-5$ & 11 & 53 & 11 & & $1: 7$ & $0 \cdot 15$ & & & $1: 3: 4$ & $\begin{array}{l}41 \cdot 01^{* * *} \\
(2 \cdot 25)\end{array}$ \\
\hline \multicolumn{11}{|c|}{$\begin{array}{l}\text { Family } 144(H 2-23 \times H 1-141) \\
\quad \text { MS } 2 \times H 1\end{array}$} \\
\hline $144-12 \times 141$ & 17 & 37 & 23 & & $1: 7$ & $5 \cdot 61^{*}$ & $1: 3$ & 0.21 & $1: 2: 1$ & $1 \cdot 05$ \\
\hline $\begin{aligned} 144-22 & \times 141 \\
H 2 & \times H 1\end{aligned}$ & 14 & 42 & 14 & & $1: 7$ & 2.95 & $1: 3$ & 0.69 & $1: 2: 1$ & $2 \cdot 80$ \\
\hline $144-1 \times 143-1$ & 8 & 16 & 38 & 21 & $1: 15$ & $3 \cdot 62$ & $1: 7$ & 0.01 & $1: 3: 4$ & $3 \cdot 85$ \\
\hline $144-5 \times 143-2$ & 7 & 41 & 18 & & $1: 15$ & 1.46 & $1: 7$ & 0.08 & $1: 3: 4$ & $\begin{array}{l}17 \cdot 68^{* * *} \\
(1 \cdot 79)\end{array}$ \\
\hline
\end{tabular}

second generation family was derived (table 6). In a number of crosses a considerable fraction of MS3 plants was observed. The MS3 phenotype was left out in calculating ratios, which is equivalent to regarding MS3 as being epistatic over MS2. This will be discussed further in the next sections. The first impression, based on the ratios MS2: $(\mathrm{IN} 2+\mathrm{H} 2)$ in the tables 5 and 6, is that the inheritance of MS2 is recessive, as the highest ratio found is $1: 1$. If there are only recessive male sterility genes, cooperating in the same fashion as the genes for MS1, MS2 plants are homozygous recessive at all loci. Expectations of the first generation crosses based on this model are shown in the first ratio column of table 5. Because none of the crosses with $\mathrm{H} 2-18$ resulted in segregation of MS2 plants, this plant is considered homozygous wild type at least at one of the loci. The other hermaphrodite parents are heterozygous at some loci and homozygous recessive at the rest. The plants $\mathrm{H} 1-39, \mathrm{H} 1-113, \mathrm{H} 2-17$ and $\mathrm{H} 2-23$ are assumed to be heterozygous at two, and $\mathrm{H} 1-141$ at three loci. This makes the minimum number of loci three. These assumptions gave the best fit for the first generation, but three out of twenty crosses did not agree with expectations (first ratio column in table 5). In all three crosses there is an excess of MS2 plants, which cannot be explained in a simple way.

A number of crosses were examined further by making second generation families (table 6). The parental cross of family 140 was $\mathrm{H} 2-17 \times$ H1-39. Both plants are considered double heterozygous and plant 
H2-140-5 is assumed to be a single heterozygote. The expectations of the crosses in this family are shown in the first ratio column. The fit is bad. However, note the reverse symmetry between crosses of MS2-140-1 and MS2-140-65 with the same parent and the correspondence between H1-39 and $\mathrm{H} 2-17$, when acting as male parents. They suggest linkage between one of the male sterility loci and the self-incompatibility $(S)$ locus. It is assumed for reasons of simplicity that only two male sterility genes $\left(m p_{1}\right.$, $m p_{2}$ ) are varying in this family (three are also possible but make no difference). The $m p_{1}$ and the $S$ locus are taken as being linked with recombination frequency $r$, and genotypes were assigned to the parents according to table 7 , which also shows the expected segregation ratios as a function of $r$. The parental cross $\mathrm{H} 2-17 \times \mathrm{H} 1-39$ was fully compatible (table 1). A joint estimate of $r$ from the crosses with MS2-140-1 and MS2-140-65 gave $r=0 \cdot 21 \pm 0 \cdot 07$. The model fits the results very well, as can be seen from the second ratio column in table 6 .

\section{TABLE 7}

Expected MS2 frequencies in the crosses in family 140 (H2-17 $\times$ H1-39) under the assumption that the $\mathrm{mp1}$ locus is linked to the $S$ locus with recombination frequency r. For crossing results see table 6

\begin{tabular}{lcccc}
\hline & & \multicolumn{3}{c}{ Male parent } \\
\cline { 3 - 5 } Female parent & Genotype & H2-17 & H1-39 & H2-140-5 \\
\hline H2-17 & $S_{1}++/ / S_{2} m p_{1} m p_{2}$ & - & $\frac{1}{16}$ & $\frac{1}{8}$ \\
H1-39 & $S_{3}++/ / S_{A} m p_{1} m p_{2}$ & - & $\frac{1}{\frac{1}{2} r}$ & - \\
MS2-140-1 & $S_{2} m p_{1} m p_{2} / / S_{4} m p_{1} m p_{2}$ & $\frac{1}{2} r$ & - \\
MS2-140-65 & $S_{1} m p_{1} m p_{2} / / S_{3} m p_{1} m p_{2}$ & $\frac{1}{2}(1-r)$ & $\frac{1}{2}(1-r)$ & - \\
H2-140-5 & $S_{1} m p_{1}+/ / S_{3} m p_{1} m p_{2}$ & $\frac{1}{4}(1-r)$ & - & - \\
\hline
\end{tabular}

The second family, 144 , originated from $\mathrm{H} 2-23 \times \mathrm{H} 1-141$, also a fully compatible cross (table 1 ). The parents have respectively two and three heterozygous loci, from the results of the first generation crosses. The $1: 15$ and 1:7 ratios in table 6 for the $\mathrm{H} 2 \times \mathrm{H} 1$ crosses in this family can easily be explained as the $\mathrm{H} 1$ parents come from the reciprocal cross (H1-141 $\times$ H2-23). However, one out of two backcrosses of MS2 progeny on the father $\mathrm{H} 1-141$, fails to give a $1: 7$ ratio as expected. A possible explanation is that one the three loci for which H1-141 is heterozygous, is $m p_{1}$. Then the backcrosses should fit a 7:29 ratio, which they both do $\left(\chi_{(1)}^{2}=0.19\right.$ and $0 \cdot 00$ ). The linkage does not necessarily have consequences for the $\mathrm{H} 2 \times \mathrm{H} 1$ crosses as they may be fully compatible.

Linkage between the $m p_{1}$ and $S$ loci can only partly explain the three deviant crosses in table 5. Disturbed ratios only occur in half-compatible crosses. $\mathrm{H} 2-23 \times \mathrm{H} 1-39$ is fully compatible (table 1 ) but MS2-13 $\times \mathrm{H} 2-17$ and MS2-43 $\times$ H2-17 were not tested sufficiently and might be half compatible. In fact, they both fit a 7:11 ratio $\left(\chi_{(1)}^{2}=1.64\right.$ and 0.09 respectively) as can be expected when linkage is involved, but the second generation family, obtained from MS2-13 $\times \mathrm{H} 2-17$, makes this explanation unlikely for this cross. The three backcrosses of MS2 progeny on the father $\mathrm{H} 2-17$ can be considered homogeneous with respect to segregation of MS2 $\left(\chi_{(2)}^{2}=\right.$ 5.49) and all fit a 1:1 ratio (table 6), as does the parental cross (table 5). 
This indicates that $\mathrm{H} 2-17$ acts in this family as a single heterozygote while it should be a double heterozygote. A similar phenomenon was observed in the third deviant cross $\mathrm{H} 2-23 \times \mathrm{H} 1-39$ which fits a $1: 7$ ratio while $1: 15$ is expected if both parents are double heterozygous. This can, for instance, result from $\mathrm{H}$ 2-23 being homozygous dominant for an epistatic factor which suppresses the expression of the wild type allele at one of the male sterility loci. Crosses between $\mathrm{H} 2-23$ and other hermaphrodites should then show a well defined excess of MS2 if they show variation at the suppressed locus. The second ratio column in table 5 shows that the fit is good. Only $\mathrm{H} 2-17 \times \mathrm{H} 2-23$ gives a slightly significant result which disappears when segregation of IN2 plants is taken into account (table 5). It also offers an alternative explanation for the cross $\mathrm{H} 2-23 \times \mathrm{H} 1-141$ and family 144 because the backcrosses of MS2 plants on $\mathrm{H} 1-141$ both fit a $1: 3$ ratio (table 6).

\section{(iii) Intermediate sex phenotypes}

The IN 1 and IN2 phenotypes will only be considered briefly. Segregation of intermediate plants of both types follows a regular pattern and seems to depend on segregation of male steriles suggesting that the same nuclear genes are involved in each case. One can think of several systems for partial male sterility. For instance, plants that are genotypically MS for all but one arbitrary male sterility gene, might have the IN phenotype (model I). Alternatively the presence of just one wild type (restoring) allele at any locus, which has recessive action of its male sterility allele, gives the IN phenotype (model II). The difference between the two systems appears from considering a plant with two wild type alleles at the same locus. It is IN in the first and $\mathrm{H}$ in the second model.

Model II was applied to the results with the IN2 phenotype under a few assumptions: the presumed epistatic factor in $\mathrm{H} 2-23$ acts in all crosses between $\mathrm{H} 2-23$ and other $\mathrm{H}$ plants and in the backcrosses of family 144; plant $\mathrm{H} 2-18$ is not only homozygous wild type at one locus, but also heterozygous at three other loci (this implies that there are at least four instead of three loci determining MS2); and the deviant crosses MS2-43 $\times$ $\mathrm{H} 2-17$ and MS2-13 $\times$ H2-17 with family 70 are left out of consideration. The results are shown in tables 5 and 6 . In 20 out of 28 crosses the fit is good. Of the crosses with significant chi-square values five have an excess of IN2 plants. Two different explanations can be given for these results. Firstly, it concerns crosses between $\mathrm{H}$ plants which means that male sterility loci can become homozygous wild type in some offspring. If model I applies and not II expectations would change in such a way that the excess of IN2 disappears. For example, in cross $\mathrm{H} 2-17 \times \mathrm{H} 1-39$ the $1: 4: 11$ ratio changes to $1: 5: 10$ or $1: 6: 9$, depending on whether the parents have one or two genes in common. As no data are available to determine this, no choice can be made between the two models. Overlapping phenotypes are the second explanation. In a previous section the inconstant behaviour of a subhermaphrodite phenotype was mentioned. If these plants are counted as $\mathrm{H} 2$ instead of IN2, the chi-square values in these crosses, which are between brackets in the tables 5 and 6 , are non-significant. The three other crosses with significant chi-square values are crosses between MS2 and H1 (table 5) and have an excess of $\mathrm{H}$ plants. No explanation is offered for these results. 
For the IN1 phenotype no distinction between models I and II can be made either, because of a lack of suitable data, most parents being fixed for the recessive male sterility genes. Both models predict the same ratios. A fairly good fit was only obtained with family 57 (table 4) and in the MS1 $\times \mathrm{H} 1$ crosses of the first generation (table 2) assuming that the ratios in the first column apply. Two kinds of deviations are worth mentioning. Firstly crosses with a $3: 1$ and $1: 1$ ratio should not segregate $\mathrm{H} 1$ plants. However they do and in a regular way: the IN1:H1 ratio is consistently $3: 1$. Secondly, in crosses between H1-141 and H1-113 with $\mathrm{H} 2$ plants (table 2) a $1: 2: 1$ ratio was expected while the low frequency of IN1 plants suggests this phenotype to be genetically absent. In both cases $\mathrm{H} 1$ plants were found where IN1 plants were expected. Possibly separate loci exist for partial male sterility of this type.

Thus for neither IN type an exact model was given. Some of the problems have already been mentioned, another one is that plants $\mathrm{H} 2-140-5$ and H1-39 should be IN2 and IN1 respectively according to their presumed genotype, but they clearly were not. The main purpose of this section was to show that the inheritance of both IN types is probably largely determined by the same genes that determine male sterility.

\section{A THIRD MALE STERILITY TYPE}

In this study a third male sterility type (MS3) was found in some crosses. It has a distinct appearance, and can be recognized by the yellow colour of the anthers. The filaments are shorter than in hermaphrodites but anthesis proceeds in a normal way. The anthers are reduced in size but not as much as in MS1 plants. They contain numerous pollen grains of which only 0.3-4.0 per cent are stainable (cf. Van Damme and Van Delden, 1982) but the anthers remain closed so that the pollen is not released. Expression of the MS3 phenotype occurs in plants with either plasmon type, $R$ or $P$, and is largely independent of environmental circumstances. The phenotype of rarely occurring intermediates is in accordance with the plasmon type of the plants. The phenotype has been described by earlier authors as " $2 \mathrm{~d}$ form hermaphrodite" or "yellow" (Bartlett, 1911) and even as separate varieties of Plantago lanceolata: var. androxanthum (Biau, 1912) and var. anthoviridis (Watson, 1937). This emphasizes its distinctive appearance. MS3 is rare in nature: it was present in only 14 out of 27 populations and its highest frequence was 0.024 (own results, but see also Bartlett, 1913).

The crosses segregating MS3 are gathered together in table 8. The results can be simply interpreted as a two locus system $\left(m y_{1}, m y_{2}\right)$ in which the double recessive is MS3. Five of the twelve original parents are involved: the results can be explained if $\mathrm{H} 2-18$ is heterozygous at both loci and MS2-13, H1-113 and H2-23 at one locus. Taking the genotype of H2-23 arbitrarily as $m y_{1}+m y_{2} m y_{2}, \mathrm{H} 1-141$ should be,$++ m y_{2} m y_{2}$. The probability that one of the four crosses in family 143 (table 4) segregates MS3 is 0.375 , which is a satisfactory value. In relatively few crosses MS 3 segregated together with one of the other two male sterility types, so there was little opportunity to examine dominance relations between them. Only the crosses $\mathrm{H} 1-113 \times \mathrm{H} 2-23$ (table 2) and MS2-13 $\times \mathrm{H} 2-23$ (table 6) are considered suitable to test the relation of MS3 with MS1 and MS2 respectively. In both crosses the two sterility types are expected to occur in one quarter 
TABLE 8

Summary of the crosses from the tables 2, 4-6 segregating MS3. In crosses between hermaphrodites results of reciprocals have been added

\begin{tabular}{|c|c|c|c|c|}
\hline \multirow[b]{2}{*}{ Cross } & \multicolumn{2}{|c|}{ Offspring } & \multirow[b]{2}{*}{ Ratio } & \multirow[b]{2}{*}{$x_{(1)}^{2}$} \\
\hline & MS3 & not MS3 & & \\
\hline $\mathrm{MS} 2-13 \times \mathrm{H} 2-23$ & 28 & 76 & $1: 3$ & $0 \cdot 12$ \\
\hline MS2-13 × H2-18 & 9 & 87 & $1: 7$ & 0.60 \\
\hline $\mathrm{H} 1-113 \times \mathrm{H} 2-23$ & 53 & 127 & $1: 3$ & 1.67 \\
\hline $\mathrm{H} 1-113 \times \mathrm{H} 2-18$ & 21 & 129 & $1: 7$ & $0 \cdot 19$ \\
\hline $\mathrm{H} 2-23 \times \mathrm{H} 2-18$ & 13 & 90 & $1: 7$ & 0.01 \\
\hline \multicolumn{5}{|l|}{ Family 143,144} \\
\hline$H 1-141 \times H 2-23$ & 0 & 203 & $0: 1$ & - \\
\hline H1 $143-1 \times$ H2-144-1 & 43 & 119 & $1: 3$ & 0.13 \\
\hline
\end{tabular}

of the progeny. If the one type is epistatic to the other, either a $3: 4: 9$ or a $4: 3: 9$ ratio should fit the data. In MS2- $13 \times \mathrm{H} 2-23$ only the MS2: MS3 : rest ratio $3: 4: 9$ agrees with observed results $\left(\chi_{(2)}^{2}=0.78\right)$, while $4: 3: 9$ deviates significantly $\left(\chi_{(2)}^{2}=6 \cdot 16^{*}\right)$, suggesting that MS3 might be epistatic to MS2. In cross $\mathrm{H} 1-113 \times \mathrm{H} 2-23$ however neither ratio fits the data $\left(\chi_{(2)}^{2}=12 \cdot 29^{* *}\right.$ and $\left.14 \cdot 74^{* *}\right)$. This leaves the relation between MS1 and MS3 unclear.

\section{Discussion}

Evidence is presented in this paper of complex inheritance of three male sterility types in Plantago lanceolata. A summary of the results is given in table 9. Both MS1 and MS2 appear to result from a number of nuclear genes interacting with a particular plasmon type. The third male sterility type, MS3, is expressed in both plasmon types and is determined by nuclear genes only. Inheritance of male sterility in Plantago lanceolata was first studied by Correns $(1906,1908)$ who did not arrive at any specified model. Reinterpretation of his data shows that he obtained 100 per cent male steriles in crosses with MS1 and over 50 per cent male steriles in crosses with MS2. The latter result was not found in the present study, but can be explained either by linkage of $m p_{1}$ and $S$ if the crosses were half compatible or by the presence of plasmon $\mathrm{R}$ in the male parents Correns

TABLE 9

Notation and minimum numbers of postulated male sterility genes for three male sterility types in Plantago lanceolata

\begin{tabular}{cccccc}
\hline & \multicolumn{5}{c}{ Male sterility genes } \\
\cline { 2 - 6 } $\begin{array}{c}\text { Male sterility } \\
\text { type }\end{array}$ & recessive & $\begin{array}{c}\text { minimum } \\
\text { number }\end{array}$ & dominant & $\begin{array}{c}\text { minimum } \\
\text { number }\end{array}$ & $\begin{array}{c}\text { with expression } \\
\text { in plasmon }\end{array}$ \\
\hline MS1 & $m r_{i}$ & 2 & $M r_{i}$ & 3 & $\mathrm{R}$ \\
MS2 & $\begin{array}{c}m p_{i} \\
m y_{i}\end{array}$ & 2 & - & - & $\mathrm{P}$ \\
MS3 & 2 & - & - & $\mathrm{R}, \mathrm{P}$ \\
\hline
\end{tabular}


used. Results of other authors are also compatible with the models in this paper. Ross (1969), probably working with MS1, proposed two duplicate recessives gene which may be identical to $m r_{1}$ and $m r_{2}$. Limited genetic studies of MS3 have been made by Bartlett $(1911,1913)$ and Watson (1937) and indicated recessiveness of the characteristic.

No phenomena like gametophytic action of male sterility genes or nuclear-induced changes in the plasmon, referred to earlier in the paper, seem to be involved in the inheritance of male sterility in Plantago lanceolata. However some features of the genetic system are worth discussing. For the inheritance of MS1 a combination of recessive and dominant male sterility genes has been proposed which together can account for the variety of ratios observed. Dominant male sterility genes per se are regarded as rare, compared with recessives (Gottschalk and Kaul, 1974). Nevertheless they have been described for a considerable number of species. In combination with a recessive male sterility gene, for example, dominants have been claimed for the wild species Origanum vulgare (Lewis and Crowe, 1956), Cortaderia richardii (Connor, 1973) and Mercurialis annua (Louis and Durand, 1978) and also for cultivated species like Zea mays (plasmon N, Schwarz, 1951), Triticum aestivum (Wickersham and Patterson, 1980), Lactuca sativa (Ryder, 1963), Phaseolus vulgaris (Mutschler and Bliss, 1980) and Petunia hybrida (Van Marrewijk, 1969).

Another point concerns differences in nuclear inheritance of male sterility types within species and within plasmon types. An example of the former case is Daucus carota which like Plantago lanceolata has two cytoplasmically determined male sterile morphs. The Petaloid type is determined by at least two dominant male sterility genes in combination with an "epistatic factor" while a number of recessive genes have been proposed for the Brown anther type (Morelock, 1974). Also, sterility expression of each type depends to some extent on environmental conditions (Michalik, 1979; Eisa and Wallace, 1969). Another example might be found in Polemonium coeruleum although cytoplasmic determination of male sterile morphology has not been sufficiently tested (Ostenfeld, 1923). Segregation of two male sterility types within crosses has been reported for Limnanthes douglasii (Jain et al., 1978) and Brassica (Pearson, 1972). In Brassica different nuclear genes were found to determine the two male sterility types and the one type appeared epistatic to the other. In Plantago lanceolata different nuclear genes were found for all three male sterility types. It would, however, require further study to find whether they have some genes in common. Also dominance relations between MS1 and MS2 on the one hand and MS3 on the other hand are largely unknown. In calculating ratios for crosses segregating two sterility types, assumptions about them had to be made but the conclusions are not seriously affected when other dominance relations are used.

The third male sterility type MS3, is expressed in both plasmon $R$ and $P$ and can therefore be called a nuclear male sterile, in contrast to MS1 and MS2 which have nuclear-cytoplasmic inheritance. This distinction in mode of inheritance, however, is usually only made for practical reasons. For instance, in Zea mays a number of independent nuclear male sterility genes are known to express themselves in plasmon $\mathrm{N}$ (Albertsen and Phillips, 1981) but they have never been tested for male sterility expression in any of the plasmon types T, S and C (Phillips, personal communication). 
This is remarkable in view of the effort that in the past decade has been put into finding new nuclear-cytoplasmic male steriles for this species.

Although intermediate sex phenotypes were not the prime object of interest in this study, some inferences can be made about them. Observations of individual plants in various conditions indicated the existence of multiple genotypes within IN1 and IN2 with overlapping phenotypes. An influence of environmental conditions on male sterility expression was observed, and is well known in cultivated species (Frankel and Galun, 1977). Genotypic determination followed from the regular segregation pattern in the crosses. Both IN1 and IN2 can probably largely be explained by incomplete dominance at the male sterility loci. Different restoration capabilities of the various wild type alleles might account for genotypic heterogeneity within the IN phenotypes. Similar models have been proposed for Mercurialis annua (Louis and Durand, 1978), Triticum aestivum (Wickersham and Patterson, 1980), Helianthus annuus (Vrânceanu and Stoenescu, 1978) and Secale cereale (Scoles and Evans, 1979). Alternatively, separate loci might exist for partial male sterility (Beckett, 1966; Stelly and Palmer, 1980). In an elaborate study on Origanum vulgare Kheyr-Pour (1980) successfully selected against intermediates in some families, a result which is in line with this possibility.

Lewis and Crowe (1956) put forward an evolutionary scheme of male sterility evolving from self-incompatibility in Origanum vulgare and suggested that there should be a connection between the two systems in Plantago lanceolata. Although an example is known of a $S$ gene participating in the determination of male sterility in Nicotiana (East, 1932), no evidence for such a relationship was found in Plantago lanceolata (see also Ross, $1969 ; 1973)$. The two systems are simply present simultaneously, which in itself is a rare condition. In all crosses made in this study the selfincompatibility system functioned as expected (Ross, 1973) in both male steriles and hermaphrodites (see also Van Damme and Van Delden, 1982). In view of the large number of genes for male sterility (table 9) and the low chromosome number $(n=6)$, linkage between one of the male sterility loci and the $S$ locus is not surprising. Interestingly a correlation between the MS1 phenotype and $S$ genotype has been found in another population of Plantago lanceolata (Van Dijk, in prep.). Under the assumption of single gene inheritance of MS1, the estimated distance between the $m r$ gene and $\boldsymbol{S}$ appeared approximately equal to the distance between $m p_{1}$ and $S$. This might indicate a common locus for MS1 and MS2.

A striking result is that the enormous genetic variation for male sterility and the resulting phenotypic variation were found in only twelve plants from a $50 \mathrm{~m}^{2}$ area. Complex inheritance of male sterility in gynodioecious species has been suspected for a long time. Correns (1928) even defined paragynodioecy as being characterised by, among other things, a simple mode of inheritance. To him it was separate from true gynodioecy, characterised by complex inheritance. Kheyr-Pour (1981) stressed the importance of plasmon polymorphism in Origanum vulgare assuming single gene inheritance within each plasmon. However it can be deduced from his own results and those of Lewis and Crowe (1956) that nuclear inheritance has to be more complex. In Plantago lanceolata the complexity mainly concerns nuclear genes. No evidence was found for a third "non-sterility" plasmon type or for subdivision of plasmon $\mathrm{R}$ or $\mathrm{P}$, as the results can sufficiently be explained on a nuclear basis, given the two plasmon types. 
Interesting questions are how this complexity in the inheritance is maintained in wild species and how it evolved. These problems have so far received little attention, as most theoretical studies have dealt either with single gene models with or without variation in plasmon type or with subsequent evolution towards dioecy. Two locus models with various types of gene interaction have been studied by Ross and Shaw (1971). Their conclusion, that male sterility can be maintained by fitness differences between sex phenotypes, irrespective of the number of nuclear genes involved or their mode of interaction, has later been generalised (Lloyd, 1975; Charlesworth, 1981; but see Gregorius et al., 1982). The mode of genetic control, however, is of importance when overdominance is involved in the inheritance of male sterility (Ross, e.g., 1978). None of these authors discusses the stability of multilocus systems or their evolution. Relevant in this respect may be the observation of Ross (1978) that in wild species only genetical systems have been found with duplicate and not with complementary interaction. Partly this is a semantic matter because if stamen function is taken as a criterion for male sterility rather than stamen morphology (cf. Ross, 1969), complementary instead of duplicate systems would have been deduced in the present study for male sterility in both plasmon types. The difference between a complementary and a duplicate system is that if one of the loci becomes homozygous for the wild type allele, in the former case a male sterile form persists while male sterility disappears in the latter case. Of course, independent male sterility genes do not necessarily give different male sterile phenotypes.

To illustrate the problem, let us consider a one locus system for male sterility. Assume, as in some of the models mentioned above, that pollination does not limit seed set, that male steriles are maintained by fitness differences between sex phenotypes and that male sterile frequency is at equilibrium. When a mutation at another locus arises so that male sterility becomes determined by two duplicate genes, it concerns necessarily a restorer mutation while that locus was previously fixed for a sterility allele. Such a new allele would not invade the population (Charlesworth, 1981) but on the other hand it would not be selected against either. Depending on the occurrence of chance effects the locus even may remain polymorphic for some time, although it can never become fixed for the new allele, provided that male steriles remain capable of maintaining themselves despite the new hermaphrodite genotypes. It can easily be shown that there is a maximum to the frequency of the new restorer allele, given the equilibrium frequency of male steriles which itself has a maximum of 0.5 in this model. However, the same chance effects can make the allele disappear again. In the long run therefore, depending on mutation frequency and chance effects, one might sooner expect a multilocus system to reduce to single locus system than the other way around. Clearly stability of multilocus systems is not achieved in this model.

The model considered is however a simplification in several respects. Other mechanisms for maintenance have been proposed in the literature and exclusively nuclear inheritance does not hold for Plantago lanceolata and probably neither for other gynodioecious species. Nuclear-cytoplasmic models, which are more likely to apply in most species, have only been studied to a limited extent (Charlesworth, 1981; Delannay et al., 1981). In conclusion, the questions of stability and evolution of complex nuclear inheritance remain unsolved. 
Acknowledgements. I thank Dr H. van Dijk for showing me his unpublished data Drs D. Charlesworth, R. Hoekstra, M. D. Ross, W. van Delden, G. van Nigterecht and J. Woldendorp for reading an earlier draft of the manuscript. I am especially grateful to H. Nijdam and A. Hamminga for their practical assistance. These investigations were supported by the Foundation for Fundamental Biological Research (BION), which is subsidized by the Netherlands Organisation for the Advancement of Pure Research (ZWO).

\section{REFERENCES}

ALbeRTSEN, M. C. AND PHILliPS, R. L. 1981. Developmental cytology of 13 genetic male sterile loci in maize. Can. J. Gen. Cyt., 23, 195-208.

BARTLETT, H. H. 1911. On gynodioecism in Plantago lanceolata. Rhodora, 13, 199-206.

BARTLETT, H. H. 1913. Inheritance of sex forms in Plantago lanceolata. Rhodora, 15, 173-178.

BECKETT, J. B. 1966. Inheritance of partial male fertility in maize in the presence of texas sterile cytoplasm. Crop Sci., 6, 183-184.

BIAU, A. 1912. Nouveautés phytographiques. Bull. Soc. Bot. France, 12, 711-716.

BOND, D. A., FYFE, J. L. AND TOYNBEE-CLARKE, G. 1966. Male sterility in field beans. III. Male sterility with a cytoplasmic type of inheritance. J. agric. Sci., 66, 359-367.

BUCHERT, J. G. 1961. The stage of genome-plasmon interaction in the restoration of fertility to cytoplasmically pollen sterile maize. Proc. Natl. Acad. Sci. USA, 47, 1436-1440.

CHARLESWORTH, D. 1981. A further study of the problem of the maintenance of females in gynodioecious species. Heredity, 46, 27-39.

CONNOR, H. E. 1973. Breeding systems in Cortaderia (Gramineae). Evolution, 27, 663-678.

CORRENS, C. 1906. Die Vererbung der Geschlechtsformen bei den gynodiöcischen Pflanzen. Ber. Deutsch. Bot. Ges., 24, 459-474.

CORRENS, C. 1908. Die Rolle der männlichen Keimzellen bei der Geschlechtsbestimmung der gynodioecischen Pflanzen. Ber. Deutsch. Bot. Ges., 26a, 686-701.

CORRENS, C. 1928. Bestimmung, Vererbung und Verteilung des Geschlechts bei den höheren Pflanzen. Handbuch der Vererbungswissenschaft, 2c, Borntraeger, Berlin.

DELANNAY, X., GOUYON, P. H. AND VALDEYRON, G. 1981. Mathematical study of the evolution of gynodioecy with cytoplasmic inheritance under the effect of a nuclear restorer gene. Genetics, 99, 169-181.

EAST, E. M. 1932. Studies on self sterility. IX. The behaviour of crosses between self sterile and self fertile plants. Genetics, 17, 175-202.

EISA, H. M. AND WALLAE, D. H. 1969. Factors influencing petaloidy expression in the carrot Daucus carota L. Proc. Am. Soc. Hort. Sci., 94, 647-649.

FRANKEL, R. AND GALUN, E. 1977. Pollination mechanisms, reproduction and plant breeding. Monographs on theoretical and applied genetics 2, Springer-Verlag, Berlin.

GANDERS, F. R. 1978. The genetics and evolution of gynodioecy in Nemophila menziesii (Hydrophyllaceae), Can. J. Bot., 56, 1400-1408.

GOTTSCHALK, W. AND KAUL, M. L. H. 1974. The genetic control of microsporogenesis in higher plants. Nucleus (Calcutta), 17, 133-166.

GREGORIUS, H.-R., ROSS, M. D. AND GILLET, E. 1982. Selection in plant populations of effectively infinite size: III The maintenance of females among hermaphrodites for a biallelic model. Heredity, 48, 329-343.

JAIN, S. K., BOUSSY, I. A. AND HAUPTLI, H. 1978. Male sterility in meadowfoam. J. Hered., 69, 61-63.

KHEYR-POUR, A. 1980. Nucleo-cytoplasmic polymorphism for male sterility in Origanum vulgare L. J. Hered., 71, 253-260.

KHEYR-POUR, A. 1981. Wide nucleo-cytoplasmic polymorphism for male sterility in Origanum vulgare L. J. Here $1 .$, 72, 45-52.

LEWIS, D. 1941. Male sterility in natural populations of hermaphrodite plants. New Phytol., 40, 56-63.

LEWIS, D. AND CROWE, L. K. 1956. The genetics and evolution of gynodioecy. Evolution, $10,115-125$.

LLOYD, D. G. 1974. Theoretical sex ratios of dioecious and gynodioecious angiosperms. Heredity, 32, 11-34.

LLOYD, D. G. 1975. The maintenance of gynodioecy and androdioecy in angiosperms. Genetica, 45, 325-339. 
LOUIS, J. P. AND DURAND, B. 1978. Studies with the dioecious angiosperm Mercurialis annua L. $(2 n=16)$. Correlation between genic and cytoplasmic male sterility, sex segregation and feminizing hormones (cytokinins). Molec. Gen. Genet., 165, 309-322.

MARTIN, F. W. 1959. Staining and observing pollen tubes in the style by means of fluorescence. Stain Technol, 34, 125-128.

MICHALIK, B. 1978. Stability of male sterility in carrot under different growth conditions. Bull. Acad. Pol. Sci. Ser. Biol., 26, 827-832.

MORELOCK, T. E. 1974. Influence of cytoplasmic source on expression of male sterility in carrot, D. carota. Ph. D. Thesis. Univ. of. Wisconsin.

MUTSCHLER, M. A. AND BLISS, F. A. 1980. Genic male sterility in the common bean (Phaseolus vulgaris L.). J. Am. Soc. Hort. Sci., 105, 202-205.

ostenFELD, C. H. 1923. Genetic studies in Polemonium coeroleum. Hereditas, 4, 17-26.

PEARSON, O. H. 1972. Cytoplasmically inherited male sterility characters and flavor components from the species cross Brassica nigra (L.) Koch $\times$ B. oleracea L. J. Am. Soc. Hort. Sci., 97, 397-402.

RHOADES, M. M. 1950. Gene induced mutation of a heritable cytoplasmic factor producing male sterility in maize. Proc. Natl. Acad. Sci. USA, 36, 634-635.

ROSs, M. D. 1967. Two genetic mechanisms governing outbreeding in Plantago lanceolata. Genetics, 56, 584-585. (Abstract.)

ROss, M. D. 1969. Digenic inheritance of male sterility in Plantago lanceolata. Can.J. Genet. Cytol., 11, 739-744.

Ross, M. D. 1973. Inheritance of self-incompatibility in Plantago lanceolata. Heredity, 30, 169-176.

ROSS, M. D. 1978. The evolution of gynodioecy and subdioecy. Evolution, 32, 174-188.

ROSS, M. D. AND SHAW, R. F. 1971. Maintenance of male sterility in plant populations. Heredity, 26, 1-8.

RYDER, E. J. 1963. An epistatically controlled pollen sterile in lettuce (Lactuca sativa $L$.). Proc. Am. Soc. Hort. Sci., 83, 585-589.

SCHWARZ, D. 1951. The interaction of nuclear and cytoplasmic factors in the inheritance of male sterility in maize. Genetics, 36, 676-696.

SCOLES, G. J. AND EVANS, L. E. 1979. The genetics of fertility restoration in cytoplasmic male-sterile rye. Can. J. Genet. Cytol., 21, 417-422.

SHINJYO, C. 1969. Cytoplasmic-genetic male sterility in cultivated rice, Oryza sativa L. II. The inheritance of male sterility. Jap. J. Genet., 44, 149-156.

SIMMONDS, N. w. 1971. The breeding system of Chenopodium quinoa. I. Male sterility. Heredity, 27, 73-82.

SNYDER, W. E. 1948. The mechanism of the photoperiodic response of Plantago lanceolata. Am. J. Bot., 35, 520-525.

STELLY, D. M. AND PALMER, R. G. 1980. A partially male sterile mutant line of soybeans, Glycine max (L.) Merr.: inheritance. Euphytica, 29, 295-303.

VAN DAMME, J. M. M. AND VAN DELDEN, W. 1982. Gynodioecy in Plantago lanceolata L. I Polymorphism for plasmon type. Heredity, 49, 303-318.

VAN MarrewiJK, G. A. M. 1969. Cytoplasmic male sterility in Petunia. I. Restoration of fertility with special reference to the influence of environment. Euphytica, 18, 1-20.

VRÂNCEANU, A. V. AND STOENESCU, F. M. 1978. Genes for pollen fertility restoration in sunflowers. Euphytica, 27, 617 627.

WATSON, W. 1937. Plantago lanceolata var. anthoviridis Wats. J. Bot. Lond., 75, 231-233. WICKERSHAM, D. S. AND PATTERSON, F. L. 1980. Male fertility restoration in crosses of R5 with soft red winter wheats (Triticum aestivum). Crop. Sci., 20, 100-102. 